\title{
Relationships as Regulators
}

\author{
Tiffany Field ${ }^{1,2}$ \\ ${ }^{1}$ Touch Research Institute, Medical School, University of Miami, Miami, USA \\ ${ }^{2}$ Fielding Graduate University, Santa Barbara, USA \\ Email: tfield@med.miami.edu
}

Received March $7^{\text {th }}$, 2012; revised April $7^{\text {th }}, 2012$; accepted May $10^{\text {th }}, 2012$

\begin{abstract}
This paper reviews the Hofer $(1984,1996)$ and Field $(1985,1994)$ models on relationships as regulators, suggesting that relationships regulate optimal stimulation and thereby modulate arousal levels and attenuate stress. In these models, the behavioral, physiological and biochemical rhythms of individuals become synchronized within close relationships like mother-infant and peer relationships both in human and animal species, and they become more coordinated over time, with some potentially remaining stable, much like zeitgebers. Hofer supports his model by data on infant rat separation stress and Field describes "psychobiological attunement" between human infants and their mothers and between young peers. This review revisits the "relationships as regulators" model, summarizing studies on relationships between non-depressed versus depressed mothers and their infants, between infant, preschool and preadolescent friends versus acquaintances and between happily versus unhappily married couples. Although some behavioral and physiological data support Hofer's and Field's "relationships as regulators" model, many studies on relationships have focused instead on the effects of separation or loss. Both Hofer and Field suggest that the real question is "what was there about the relationship that was then missing after the loss?” Future research could address the question of potential mediators and underlying mechanisms for relationships becoming regulators. Potential mediators are explored here including mirror neurons, affective priming, imitation and empathy. The individuals' rhythms and the attraction to others' rhythms as regulators may be an epigenetic programming phenomenon, suggesting both genetic and early experience effects that endure across development.
\end{abstract}

Keywords: Relationships; Psychobiological Attunement; Arousal; Separation

\section{Introduction}

This paper reviews models on relationships as regulators advanced by Hofer $(1984,1996)$ and Field $(1985,1994)$. In their model, relationships are seen as regulating optimal stimulation and arousal levels for the purpose of controlling stress. This phenomenon can be seen in behavioral, physiological and biochemical synchrony in relationships across development from mother-infant interactions to young peer interactions to those of older couples. Much of the literature has focused on the effects of separation and loss rather than the mediating variables or the ways in which relationships become regulators. Some potential mediators are reviewed here including mirror neurons, affective priming, imitation and empathy. Examples are given of early mother-infant interactions from different species as illustrative of the epigenetic programming that may contribute to an individual's rhythms and the attraction to others as regulators.

Hofer $(1984,1996)$ and Field $(1985,1994)$ advanced models on relationships as regulators of stimulation and arousal modulation and tested them on mother-infant rat and mother-infant human relationships. Although these models inspired a significant body of research, they have not been embraced by the scientific community. Neuroscience data have suggested potential mediators for relationships as regulators including mirror neurons, affective priming, imitation and empathy. This paper reviews data on those models and suggestions for future research.

In his seminal paper on "relationships as regulators", Hofer described how he discovered this model when the mother rat was separated from her offspring, and distress cries and physiological disorganization ensued (Hofer, 1984). He referred to these changes following the separation as "perhaps resulting from withdrawal of specific sensory motor regulators”. He also alluded to the sensory deprivation of explorers, shipwrecked sailors, prisoners and those in solitary confinement studies in which similar chronic symptoms occurred. He described the behavior following the loss of another person as desynchronization. As Hofer noted, “...nonverbal signals, mannerisms, tones of voice, gestures, facial expressions, brief touches, and even the timing of events and pauses between words may have physiological consequences, often outside of awareness" (Hofer, 1984). He concluded that paper with a note on the importance of looking at the relationship "before the loss occurred rather than beginning after the loss”.

Hofer later posed the question "How can the absence of something or somebody cause such disturbance?” (Hofer, 1996). He cited several examples from animal models including his own work on providing heat as a mother substitute for infant rat pups as well as the work of others on the moving terrycloth surrogate mother for Rhesus monkey infants who had become disorganized following separation from their mothers (Mason \& Berkson, 1975). Several neuroscientists have presented data showing the survival value of the mother rat's tongue licking for excretion and for increased growth hormone in the heart, liver and brain as well as for "turning-on the growth gene" (see Schanberg \& Field, 1987, for a review). Further, increased tongue licking and grooming (LG) and arched-back nursing (ABN) by rat mothers have altered the offspring's glucocorti- 
coid receptors in the hippocampus (Weaver et al., 2004). Offspring of mothers that showed high levels of LG and ABN were found to differ in DNA from those with low levels. These differences emerged over the first week of life, were reversed with cross-fostering and persisted into adulthood. They were also associated with altered glucocorticoid receptors observed among the infant rats following maternal separation.

Hofer also borrowed examples from the human contact literature to make his point that physical contact had organizing effects. He noted the synchrony in menstrual cycles after women started living in groups (McClintock, 1983; Weller \& Weller, 1993), how social interactions facilitated recovery from jet leg (Klein \& Wegmann, 1974), and how, in contrast, sensory deprivation could have extremely disorganizing effects (Heron, 1961). He also referred to external regulators as substituting for a natural regulator, citing an example from our research on massaging preterm infants to reduce touch deprivation while the preemies were in incubators separated from their parents (Field, Schanberg, Scafidi, Bauer, Vega-Lahr, Garcia et al., 1986). However, as Hofer suggested, the supplemental stimulation may not replace the normal sensory motor stimulation that would have taken place within the mother's uterus. Again, he suggested "looking carefully for exactly what was lost when loss occurs".

\section{A Deficit Model of Loss}

Human bereavement has been characterized by similar behaviors including agitation, crying, aimless activities/inactivity, sighing, respiration and muscular weakness (Shear \& Shair, 2005). These authors quoted Hofer from his 1996 paper saying that "The central characteristic of the disturbance is the failure of the normal smooth modulation and coordination of affect, behavior and physiological function into a stable daily pattern. This is felt by the individual as a sense of internal disorganization. Visual tasks, attention, concentration, sleep, food intake, and mood become fragmented" (Shear \& Shair, 2005: p. 582).

Shear and Shair (2005) cited many studies of married couples who have different combinations of secure and insecure attachment configurations, as if espousing the Bowlby (1982) attachment model. Although, midway through their paper, they returned to the important Hofer statement that “...disrupted hidden biobehavioral regulators may also cause problems for bereaved people." For example, some have shown that both the frequencies of performing simple daily activities and the regularity with which these activities are performed are an important part of circadian rhythms that get disrupted with loss of the partner (Monk, Houck, \& Shear, 2005). Dysregulation of the system can result in dysphoric emotions as well as disrupted physiological functioning. Disturbance in the pattern of daily activities could occur during bereavement because of the loss of stimulation and arousal modulation provided by the partner during those activities, much like the zeitgeber provided by the circadian light/dark cycle (Field, 1985). Consistent with this idea, Monk et al. (2005) found significant reductions in social rhythm activity levels in patients with complicated grief (Monk et al., 2005). Thus, some researchers have supported Hofer's animal model data with research on humans experiencing relationships as regulators.

\section{Social Pain}

Research on social pain was also inspired by Hofer. For ex- ample, Chen, Williams, Fitness, and Newton (2008) referred to the statement by James (1950) "If no one turned around when we entered, answered when we spoke, or minded what we did, but if every person we met 'cut us dead,' and acted as if we were non-existing things, a kind of rage and impotent despair would ere long well up in us, from which the cruelest bodily tortures would be a relief" (James, 1950). James argued that people would prefer physical over social pain (Chen et al., 2008).

As Chen et al. (2008) further noted in a paper "When hurt will not heal" four studies documented that social pain was as real and intense as physical pain. As these authors suggested, the social pain system may have "piggy backed" on the brain structure that evolved earlier for physical pain. Individuals in these studies relived and re-experienced social pain more readily and more intensely than physical pain, and, they performed worse on cognitively demanding tasks after they relived social pain than physical pain.

Functional magnetic resonance imaging studies confirmed that social pain was equivalent to physical pain (Eisenberger, Lieberman, \& Williams, 2003; Singer, Seymour, O’Doherty, Kaube, Dolan, \& Frith, 2004). In the Eisenberger et al. (2003) study, social pain like physical pain increased activity in the anterior cingulate cortex and the right ventral prefrontal cortex. In the study by Singer et al. (2004), functional imaging was conducted while participants experienced a painful stimulus and compared it to the same painful stimulus being experienced by a loved one who was present in the same room. Again, the anterior cingulate cortex was activated when the participants perceived pain and also by a signal that a loved one experienced pain. The activation of this region also correlated with empathy ratings.

\section{Heartbreak}

Social pain has also been illustrated by data showing the similarity of heartbreak or a broken heart and real heart attacks (Wittstein, Thiemann, Lima, Baughman, Schulman, Gerstenblith, et al., 2005). In this study, the pain and the other symptoms after loss of a loved one were so similar to a real heart attack that physicians were unable to differentiate the two syndromes without performing an angiogram. The physical pain in the heart or chest, a condition they called "broken heart syndrome" is thought to result from a release of catecholamines by the brain following the trauma of breaking up or losing someone. The catecholamines reportedly weakened the heart muscle and, although the heartache simulated symptoms of a heart attack, those with broken heart syndrome typically had fewer risk factors for heart disease, and they usually recovered faster than those who had real heart attacks (Wittstein et al., 2005). Although significantly elevated norepinephrine and epinephrine levels were noted in the bloodstream of the individuals with broken heart syndrome, and although they experienced symptoms similar to a real heart attack including chest pain, fluid in the lungs, shortness of breath and heart failure, the angiograms revealed no blockages in the arteries of the heart (Wittstein et al., 2005). Also, blood tests failed to reveal elevated levels of cardiac enzymes that get released into the bloodstream from damaged heart muscle during real heart attacks. Again the focus was on loss, which is understandable given that the broken heart syndrome was precipitated by loss. 


\section{Psychobiological Attunement}

In a paper similar to Hofer's (1984) paper, relationships as regulators were referred to as "Psychobiological Attunement" (Field, 1985). Many of the studies reviewed there also focused on lost relationships rather than the critical qualities of relationships. For example, we studied separations between mothers and infants (when mothers were hospitalized for childbirth), separations between young peers (who were moved to new classes or new schools) and the romantic break-ups between university students.

\section{Mother-Child Separations}

In the childbirth study, mothers were separated from their infants, toddlers or preschoolers for the birth of another child (Field \& Reite, 1984). The children were agitated during their mothers' hospitalization, showing increased negative affect, activity level, heart rate, night wakings and crying. Longer than usual periods of deep sleep at this stage were interpreted as conservation withdrawal.

After the mother returned, decreases were noted in positive affect, activity level, heart rate, and active sleep, effects that are suggestive of depression. The parents also reported illnesses, clinging and aggressive behaviors as well as changes in eating, toileting and sleep patterns. Typically, the mothers were tired, and some experienced postpartum depression, suggesting that the mother remained unavailable to the child despite her physical presence. Inevitably, the mother-child relationship was altered by the arrival of the new sibling. The children were clearly agitated by being separated from their mothers even though they were cared for by their fathers. The fathers may not have been providing optimal stimulation or modulation of their children's arousal because of their lesser experience with the child's stimulation and arousal modulation needs. The children's depression could have been a homeostatic mechanism offsetting the arousal or agitation, or it might have resulted from inadequate stimulation.

We then compared the children's responses to separations due to their mothers' hospitalizations for the birth of another child and separations for their mothers' conference trips to explore whether it was the separation per se that was stressful or the altered parent-child relationship following the birth of the sibling (Field, 1991). As can be seen in Table 1, a number of significant differences emerged. The parents reported that more sleep and behavior problems occurred during the hospital than the conference trip separations. In addition, less smiling was noted during the play observations, and the children spent a greater proportion of their nap time in active sleep. This latter difference was interpreted as conservation withdrawal. The children's greater agitation during the hospital as opposed to the conference separations may have exhausted them more, leading to more sleep. Following the return of the mother, the parents continued to report more sleep and general behavior problems in their children following the hospital as opposed to the conference trip separations. Those children also showed less smiling, less fantasy play and fewer positive verbal interactions. Thus, the hospital separations were more stressful for the children than the separations for conference trips, possibly because the children were anticipating the arrival of a new sibling that had been explained by the parents as well as the children's anticipated change in their relationship with their parents,
Table 1.

Means for children's behaviors observed during separation and after the mother's return from a conference trip versus a hospitalization for the birth of a sibling (all group mean differences significant at $p<.05$ ) (Adapted from Field, 1994).

\begin{tabular}{lcc}
\hline & \multicolumn{2}{c}{ Type of Separation } \\
\cline { 2 - 3 } Observation Period & Conference Trip & Hospitalization \\
\hline Separation & 1.0 & 2.4 \\
Sleep problems (rating) & .7 & 1.6 \\
Behavior problems (rating) & 7.4 & 2.7 \\
Smiling (\% time) & 4.3 & 10.8 \\
Active sleep (\% time) & & \\
After mother’s return & .6 & 2.4 \\
Sleep problems (rating) & .8 & 1.6 \\
Behavior problems (rating) & 8.9 & 5.4 \\
Smiling (\% time) & 13.1 & 4.9 \\
Positive verbal interaction (\% time) & 38.7 & 23.2 \\
Fantasy play (\% time) & & \\
\hline
\end{tabular}

namely having to now share those relationships with their sibling. Separation from parents has been linked to stress responses including elevated cortisol levels that have been noted during daycare versus being at home, especially when experiencing low quality daycare where the separation from parents is particularly stressful (Geoffrey, Cote, Parent, \& Seguin, 2006). A meta-analysis has also shown higher cortisol levels during daycare versus being at home (Vermeer \& van Ijzendoorn, 2006).

\section{Infant-Peer Separations}

Children show similar symptoms when they lose each other, as was observed in a study on separation stress of nursery school infants and toddlers graduating to new classes (Field, Vega-Lahr, \& Jagadish, 1984). The play behaviors and sleep patterns of infants ( $\mathrm{M}$ age $=15$ months) and toddlers ( $\mathrm{M}$ age $=$ 2 years) were observed during the first and fourth week of the month preceding and following their graduation to new nursery classes. As compared to baseline, observations during the week preceding graduation and the week following graduation to a new class revealed greater amounts of fussing, verbal interaction, physical contact (both affectionate and aggressive), wandering, and fantasy play. Activity levels were elevated and absenteeism was more frequent. Latency to sleep was longer, more crying occurred preparatory to sleep and a lesser percentage of nap time was spent sleeping. The infants as compared to the toddlers were less agitated just prior to graduation, but more agitated during the first week in their new class. Those infants/toddlers who moved to a new class with a close friend were less distressed by the transfer than those who did not move with a close friend.

\section{Breakup Distress in University Students}

The distressful effects of losing a relationship as a regulator are further illustrated by research on breakup distress in university students after losing a romantic partner. In the first of our series of studies on university students' breakup distress, 37\% 
of the variance on Breakup Distress Scale scores was explained by depression, feelings of betrayal, having less time since the breakup and assigning a higher rating to the relationship that had been lost (Field, Diego, Pelaez, Deeds, \& Delgado, 2009). In a study on a second sample, intrusive thoughts contributed to $28 \%$ of the variance (Field, Diego, Pelaez, Deeds, \& Delgado, 2012a). Depression and sleep disturbances were also related to breakup distress in this sample. Other negative emotions and behaviors included anxiety, anger, disorganized behavior and inferior academic performance (Field, Diego, Pelaez, Deeds, \& Delgado, 2012b). Studies on the reasons for breakups revealed that insecurity (Pelaez, Field, Diego, Deeds, \& Delgado, 2011) and loss of intimacy (Field, Diego, Pelaez, Deeds, \& Delgado, 2010) were the most significant relationship problems leading to breakup. Although female students typically reported greater breakup distress, these studies are limited in their generalizability because the sample was primarily Hispanic female psychology students. Nonetheless, the data highlight the negative effects of breakup distress for university students.

\section{The Loss of Stimulation and Arousal Modulation}

In the model we called "psychobiological attunement" or "being on the same wavelength," each partner provides meaningful stimulation for the other and has a modulating influence on the other's arousal level (Field, 1985). Both excessive stimulation and inadequate stimulation (according to the individual's thresholds for optimal stimulation) are aversive, while stimulation that brings or keeps an individual within an optimal arousal zone is considered reinforcing. Excessive stimulation tends to produce over-arousal that is aversive, and too little stimulation leads to boredom and sub-optimal levels of arousal that are also aversive. Thus, loss of a relationship means the loss of both activating and calming stimulation. The individual experiencing the loss would be expected to fluctuate or vacillate between one end of the continuum of under-stimulation to the other end of the continuum of over-stimulation and not be able to regulate or modulate these levels to experience optimal levels of stimulation/arousal.

Other terms we have used are synchrony between partners and sharing rhythms. Synchrony is a term that is usually applied to the matching of rhythms in the physiological or physical activities of individuals. Examples of this can be seen in partners who are extremely close tending to coordinate their physical movements and expressions while talking, and their cortisol cycles tending to be synchronized on weekends when they are together (Field, 1985). Thus, attunement or "being on the same wavelength" happens for behavioral, physiological, and even biochemical rhythms of the individuals in the relationship. Seemingly, this could happen if each partner of the dyad is sensitized or sensitive and responsive to each other's stimulation and arousal-modulation needs, as in a feedback loop, and each accordingly adjusts his or her behavior to facilitate the synchrony of the dyad.

Physical intimacy can enhance attunement (Field, 2010b). By physical closeness/touch, individuals can learn each other's stimulation and arousal-modulation needs. Although it is possible to self-regulate in the absence of an intimate partner, it may not be as easy or effective. When a partner is no longer there, and touch-stimulation for example is missing, dysregulation may occur. Disruption of attunement may lead to physiological disorganization, to depressed behavior in some cases, and to changes in the immune system. Separation from the relationship may result in physiological and behavioral dysregulation simply because the source of stimulation and arousal modulation that maintained the individual's behavioral and physiological organization is no longer present.

Examples of relationships as regulators or attunement in relationships can be found across the lifespan, and developmental changes may occur in the thresholds for stimulation and arousal modulation. For example, thresholds for stimulation may be lower in infancy and old age, thus requiring lower levels of stimulation and greater arousal modulation (Field, 2010b). The immature infant is more readily aroused and more needy of the parent's arousal modulation.

\section{Parent-Infant Interactions}

The infant and the parent appear to synchronize their behaviors and their gaze patterns in tandem, as in a dance, with the parent necessarily being sensitive to changes in the infant's arousal and the infant, in turn, responding to the parent's sensitive behaviors. This phenomenon has been demonstrated by many researchers (Papousek, 2007; Stern, 2004; Trevarthen, 1979; Tronick, 2003). In the Papousek (2007) study, for example, infants in one group showed signs of difficult temperament including hypersensitivity and problems in arousal regulation. They were able to keep a certain balance as long as they received intense stimulation but became disorganized in response to the lack of stimulation. The mothers responded contingently with intensified stimulation to any sign of fatigue or hypoarousal on the part of the infant in order to avoid excessive crying. But they failed to provide what these inconsolable infants would have needed the most, namely reduction of stimulation, calming and settling to sleep. Infants in another group had already learned to use more or less dysfunctional regulatory strategies (gaze avoidance, staring and withdrawal) for coping with their mothers' highly intense, intrusive stimulation. Parents who show sensitivity to the affective and attentive rhythms of their infants are able to adjust their behaviors and accordingly bring the infant to a more organized state (Field, 2007). Because of the immaturity of the infant, much of the synchrony of the interaction is dependent on the parent. If parents fail to provide optimal levels of stimulation and modulate their stimulation as the infant's arousal level rises, the infant begins to show more gaze aversion and fussiness, thus disrupting the synchrony of their interaction (Field, 2007).

Elevated heartrate, gazing away and negative affect of infants during their interactions with parents may relate to an information overload and elevated arousal levels deriving from excessive stimulation (Field, 2007). In their natural attempts to elicit positive affect, some parents provide excessive stimulation and fail to modulate arousal as their infants become distressed (Paponsek, 2007). As we have also noted, the heartrate curves of mothers and infants parallel each other during interactions, with increases in heartrate noted in both mothers and infants during stressful, disturbed interactions and parallel decreases during more harmonious interactions, suggesting physiological attunement (Field, 2007).

In a study by Feldman and Eidelman (2007), mother-infant and father-infant gaze synchrony were associated with greater vagal activity in the infants. The authors suggested that when the parents were better able to coordinate their gaze with their infants' gaze, the infants showed greater vagal activity. Parents' 
regulatory activity would invariably contribute to regularity of infant behavior. In another recent study, the regularity of infant behavior at age one month based on parents being "regulators" significantly predicted the child's attentiveness and anxiety levels (negative correlation) at five different time points from kindergarten through ninth grade (Monk et al., 2010).

High-risk parents such as depressed mothers have difficulty modulating their stimulation and being in synchrony with their infants (Field, 2007). In a study on depressed and non-depressed mother-infant dyads (Field, Healy, Goldstein, \& Guthertz, 1990) interaction synchrony was assessed when the infants were 3-months-old. The mothers' and infants' attentive and affective behavior states were coded on a continuum from negative to positive including angry, disengaged, attentive and playful states. The non-depressed mothers and infants spent more time together in positive behavior states, and the depressed mothers and their infants shared more time together in negative behavior states. Shared behavior states occurred less often for the depressed dyads than for the non-depressed dyads (see Figure 1).

In another study, both behavioral states and heartrate were subjected to cross-spectral analysis (Field, Healy, \& LeBlanc, 1989). The data were analyzed to determine the coherence of the mothers' and infants' behavior and the mothers' and infants' heart rate. Coherence has been used as a statistical term to indicate concordant or synchronous activity between two data streams independent of the variable measured. The nondepressed mothers and their infants had greater coherence in their behaviors than the depressed dyads. Models of the wave forms of these mother-infant behavior states for the non-depressed and depressed dyads are given in Figures 2 and 3. The model wave forms illustrate the rhythmic structure of the interaction. Examples of synchrony can be seen at the points where the waveforms of the mothers' and infants' behavior states are similar in direction and form. The non-depressed mothers' and infants' heartrate were also more coherent than the heartrate of the depressed mothers and infants. Greater coherence was also shown in the non-depressed mothers' heartrate and their infants' behaviors which was not surprising given that non-depressed mothers are noted to be more sensitive/responsive to their infants' behaviors and that appears to be reflected in their heartrate responses to their infants' behaviors.

This model of an interactive "dance" characterized by synchrony and attunement has been challenged by data suggesting that synchrony is achieved less than $30 \%$ of the time in motherinfant dyads (Tronick, 2003). Tronick and colleagues have devoted more attention to how infants learn interactive "repair". Nonetheless, the synchrony/attunement model has continued to serve as a criterion for harmonious early interactions.

\section{Concordance in Play Behaviors and Physiology of Preschool Friends}

Concordance has also been noted among young friends in several studies. For example, close friend preschool pairs show concordance in their play behavior (Roopnarine \& Field, 1984). Concordance has also been noted in the heartrate patterns of kindergarten children playing together in their classroom (Wade, Ellis, \& Bohrer, 1973). Still another example is that the cortisol cycles of preschool playmates have been notably concordant during school days, but not on weekends (Montagner, Restoin, \& Henry, 1982).

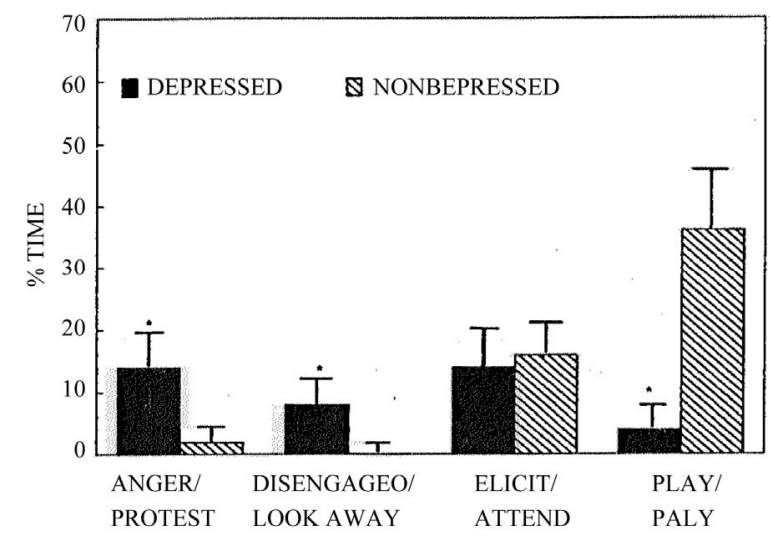

Figure 1.

Mean percent time mothers and infants shared behavioral states (standard deviations are indicated by vertical lines and asterisks indicate statistically significant differences between adjacent bars). (Adapted from Field et al., 1990).

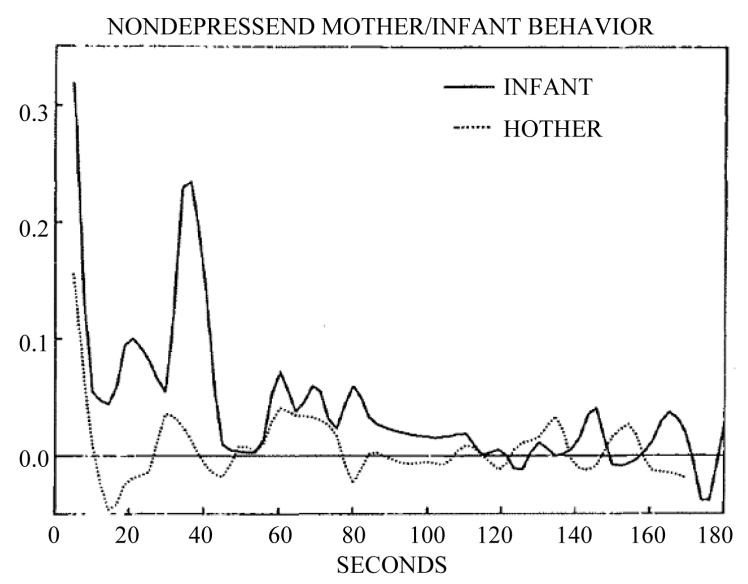

Figure 2.

Similar wave forms for nondepressed mothers and their infants suggest greater concordance in their behaviors. (Adapted from Field et al., 1989).

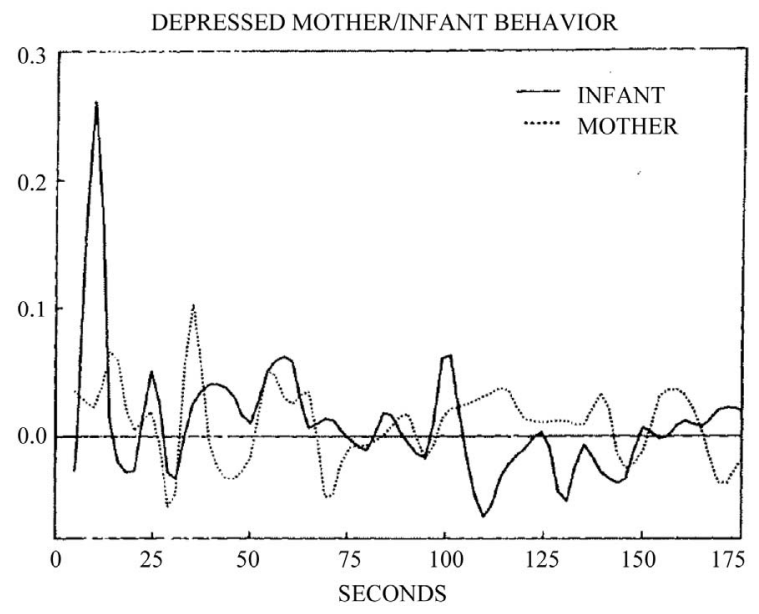

Figure 3.

Wave forms for depressed mothers and their infants moving in opposite directions suggest less concordance of their behaviors. (Adapted from Field et al., 1989). 
In a study we conducted, preschool close friends were identified by behavioral observations of classroom play, by sociograms and by child and teacher sociometric ratings (Goldstein, Field, \& Healy, 1989). Preschool close friend pairs as compared to acquaintance pairs showed greater concordance on play behaviors including parallel play and imitation (see Table 2). Greater concordance was also noted in the heartrate of close friend pairs than acquaintance pairs. And, finally, the cortisol levels of close friend pairs were more concordant than those of acquaintance pairs. In addition, cortisol levels were more elevated when the children were playing with their acquaintances than when they were playing with their friends, suggesting that their play interactions with close friends were less stressful than they were with acquaintances. The greater concordance of behavior, heartrate and cortisol suggests that behavioral, physiological, and biochemical attunement can occur in close relationships between children as early as preschool age.

In a similar study by our group, preschoolers were asked to identify their preferred playmates (Roopnarine \& Field, 1984). Analyses conducted on close friend pairs suggested that they spent a greater percent time in fantasy play and verbal interaction (positive, negative and neutral) as well as time spent making requests, using imperatives and directing and submitting to each other (see Table 3). As we suggested, it is not clear whether the children were initially matching on these behaviors or whether the matching of behaviors evolved during the course of their friendship formation. These data suggest, nonetheless, that close preschool friends appear to interact very similarly.

\section{Concordance of Behavior and Physiology in Pre-Adolescent Friends}

Surprisingly very little research has been conducted on the concordance of face-to-face interaction behavior and physiology in close friend pairs among older children and adolescents. In our research on pre-adolescents, comparisons were made between close friend pairs and acquaintance pairs to determine whether their behavior and physiology were synchronized (Field, Greenwald, Morrow, Foster, Guthertz, Healy et al., 1992). The pre-adolescents reported more positive feelings and greater liking for the interactions they experienced with close friends versus acquaintances. The close friend pairs were more attentive toward each other, more affectively positive, more vocal, more active and more playful with each other. The group of best friend dyads also had lower cortisol levels, suggesting that they were less stressed by their interactions (see Table 4).

Table 2.

Concordance for behaviors of preschoolers interacting with friends and with acquaintances. Smaller numbers indicate greater concordance (or less variance). (Adapted from Goldstein et al., 1989).

\begin{tabular}{lccc}
\hline Variable & Friends & Acquaintances & $p$ \\
\hline Fantasy play & 132.7 & 77.6 & \\
Solitary play & 145.2 & 143.4 & \\
Parallel play & 2.1 & 18.1 & .001 \\
Commands & 82.9 & 145.7 & \\
Requests & 16.1 & 42.8 & .05 \\
General conversation & 66.0 & 126.9 & \\
Following/imitating & 3.0 & 8.4 & .05 \\
\hline
\end{tabular}

Table 3.

Percent time individuals spent in different behaviors when playing with their close friends versus with acquaintances (children who were not close friends). Interobserver reliability coefficients in parentheses. (Adpted from Roopnarine \& Field, 1984).

\begin{tabular}{lccc}
\hline Behaviors & $\begin{array}{c}\text { Children with } \\
\text { Friends }\end{array}$ & $\begin{array}{c}\text { Children without } \\
\text { Friends }\end{array}$ & $p$ \\
\hline Fantasy play (88) & 25.25 & 6.83 & .05 \\
Positive Verbal & 24.88 & 10.00 & .005 \\
Interaction (96) & 16.62 & 3.58 & .005 \\
Negative Verbal & & & \\
Interaction (90) & 50.69 & 29.17 & .005 \\
Neutral Verbal & 61.86 & 33.58 & .005 \\
Interaction (86) & 2.37 & .00 & .05 \\
Statements (93) & 19.44 & 8.08 & .05 \\
Requests (100) & 6.62 & 4.17 & \\
Imperatives (96) & 28.31 & 12.33 & .01 \\
Questions (96) & 4.25 & 1.16 & .01 \\
Directing (99) & 3.06 & 5.00 & \\
Submitting (100) & 1.69 & 3.67 & \\
Giving (99) & 12.44 & 6.83 & \\
Taking (99) & 1.94 & 1.83 & \\
Sharing (98) & 6.56 & 4.08 & .005 \\
Helping (100) & 12.13 & 35.67 & \\
Imitating (100) & 12.06 & 11.08 & \\
Watching (88) & & & \\
Fighting (95) & & & \\
\hline
\end{tabular}

Greater concordance was noted within friendship pairs for attentiveness, vocal activity, activity level, physical attractiveness, involvement and relaxation ratings. These data suggest that close friend pairs not only have more fun during their interactions (i.e. they like them more and they feel more positive about them), but they also show greater similarity or concordance on a number of behaviors.

Coordinated vocal activity has also been noted in best friend pairs. In a study we conducted on pre-adolescent best friend versus acquaintance pairs, vocal activity was coded by inputting the audio signals from each person into a computer system known as the Automated Vocal Transaction Analyzer (Feldstein \& Field, 2002). Vocal states were then determined including speaking turns, switching pauses and simultaneous speech or joint speech which was categorized as non-interruptive or interruptive. The best friend pairs tended to coordinate the durations of their vocal behaviors with each other more often than the acquaintance pairs, and the girl-girl pairs coordinated the durations of their pauses significantly more often than the boy-boy pairs, suggesting that the girl-girl pairs may have been more attentive and involved in their interactions than the boys were with each other.

\section{Interpersonal Regulation in Adults}

Most of the interpersonal regulation studies on adults have been conducted with married couples by Gottman and his colleagues (Gottman \& Levenson, 2002). Many of the co-regulation behaviors that have been observed in mother-infant interactions and child-child interactions have not yet been explored during marital interactions such as the switching pauses 
Table 4.

Means for self-ratings, observer ratings, interaction behavior states, joint states, and biochemical/physiological measures of friends and acquaintances among pre-adolescents. (Adapted from Field et al., 1992).

\begin{tabular}{|c|c|c|c|c|c|}
\hline \multirow[b]{3}{*}{ Measure } & \multicolumn{4}{|c|}{ Group } & \multirow[b]{3}{*}{$p$} \\
\hline & \multicolumn{2}{|c|}{ Friends } & \multicolumn{2}{|c|}{ Acquaintances } & \\
\hline & M & SD & M & SD & \\
\hline \multicolumn{6}{|l|}{ Self-ratings } \\
\hline Feelings & 4.1 & .5 & 3.8 & .5 & .01 \\
\hline Liking & 3.8 & .8 & 3.5 & .8 & .005 \\
\hline \multicolumn{6}{|c|}{ Observer ratings } \\
\hline Attentiveness & 3.3 & .6 & 2.5 & .7 & .001 \\
\hline Affect & 3.0 & .9 & 2.3 & .6 & .001 \\
\hline Vocalizations & 3.1 & .7 & 2.5 & .6 & .001 \\
\hline Activity level & 2.7 & .8 & 2.1 & .9 & .001 \\
\hline Involvement & 3.8 & .7 & 2.6 & .8 & .001 \\
\hline Relaxation & 3.7 & .6 & 2.9 & .7 & .001 \\
\hline Playfulness & 2.6 & 1.2 & 1.8 & 1.0 & .001 \\
\hline Global rating & 3.5 & .8 & 2.3 & .8 & .001 \\
\hline Attractiveness & 3.0 & 1.5 & 2.5 & 1.6 & \\
\hline \multicolumn{6}{|c|}{ Behavior states (\% time) } \\
\hline Disengaged & 1.2 & 2.8 & 5.7 & 9.2 & .001 \\
\hline Neutral & 15.7 & 19.0 & 46.1 & 23.2 & .001 \\
\hline Interested & 59.1 & 19.4 & 46.5 & 22.7 & .005 \\
\hline Animated & 7.7 & 8.8 & .9 & 3.4 & .001 \\
\hline Playful & 16.4 & 19.5 & .9 & 3.9 & .001 \\
\hline \multicolumn{6}{|c|}{ Joint states (\% time) } \\
\hline Disengaged & .0 & .0 & .4 & .4 & .005 \\
\hline Neutral & .8 & .5 & 1.2 & .5 & .05 \\
\hline Interested & 41.3 & 21.7 & 18.9 & 13.9 & .005 \\
\hline Animated & 2.3 & .4 & .2 & .2 & .005 \\
\hline Playful & 1.8 & .5 & .4 & .7 & \\
\hline \multicolumn{6}{|c|}{ Physiological measures } \\
\hline Cortisol levels & .60 & .34 & 1.06 & 1.0 & .001 \\
\hline Heart period & 660.1 & 73.0 & 660.4 & 73.6 & \\
\hline Vagal tone & 6.1 & 1.1 & 6.1 & 1.0 & \\
\hline
\end{tabular}

and speaking turns just described for preadolescents. Studies have been conducted on the matching of positive and negative affect states and on the linkage of physiological activity (Carrere \& Gottman, 1999; Gottman \& Levenson, 2002; Gottman et al., 2003). Specifically, co-regulation has been documented for behavioral states, for physiological measures including heartrate and galvanic skin response (Levenson, Carstensen, \& Gottman, 1994), for biochemical measures such as cortisol (Loving, Crockett, \& Paxson, 2009) and for the relationships between dysregulation or the absence of co-regulation and immune and health measures (Robles \& Kiecolt-Glaser, 2003). In addition, comparisons have been made across gender, across different age groups and across similar and dissimilar personal- ity couples.

\section{Behavioral Regulation}

Although behavior matching has not been studied in adults to the same extent as it has in mother-infant dyads and in preschool and preadolescent friend pairs, the linkage between positive affect in partners and between negative affect in partners has been studied by Gottman and his colleagues (e.g. Carrere \& Gottman, 1999). Others have studied interpersonal regulation defined as changing behaviors so as to coordinate with one another (Rusbult, Kumashiro, Kubacka, \& Finkel, 2009). Still others have talked about partners who are attached to each other providing affect regulation by "offering comfort and support, making us laugh, communicating empathy, extending a listening ear, distracting us from our problems, and sharing in our successes" (Diamond, Hicks, \& Otter-Henderson, 2008). They refer to the importance of day to day proximity, offering data that those who have longer phone conversations during separations have less relationship distress. As Diamond et al. (2008) have suggested, interpersonal regulation is achieved by individuals modulating their affective responses to internal and external stimuli or by partners reciprocally regulating one another's psychological and physiological states.

\section{Physiological Regulation}

Co-regulation of physiological states has been studied by a number of investigators. In one model on co-regulation of physiology, the authors suggested that co-regulation relies heavily on a model of co-mingled physiology between romantic partners and has been variously called co-regulation, attunement and social zeitgebers (Sbarra \& Hazan, 2008). These authors described a model very similar to those models that had been advanced earlier by Hofer (1984) and by Field (1985). Co-regulation was said to be an up or down-regulation of the partners' physiological arousal which was considered a property of the relationship as opposed to either individual alone and was described as occurring via several modalities (touch, smell, eyecontact, cognition). Sbarra and Hazan (2008) also suggested that sexual and physical intimacy are the strongest physiological reward systems for romantic partners, "providing the most efficient and metabolically cost-effective means of regulating affect by synchronizing physiological systems to those of their partners."

Several studies have been conducted on the concordance of adult partners' heartrate, pulse transit time, skin conductance level and body movements (Levenson \& Gottman, 1983, 1985, 1992, 1994). They assessed the degree to which each spouse's physiological activity across those four measures could be predicted from the other's activity. Physiological interrelatedness or what they referred to as linkage between the spouses accounted for over $60 \%$ of the variance in marital satisfaction (Levenson \& Gottman, 1983). Over 80\% of the variance in satisfaction change over a three-year-period was accounted for by heartrate. Physiological linkage was a better predictor of current levels of marital satisfaction, and mean physiological levels were better predictors of future levels of marital satisfaction. The more aroused the partners were, the greater the satisfaction declined. As marital satisfaction declined, the husband's and wife's health declined. Although other factors could have contributed to the health decline, a significant amount of the variance in health was explained by marital satisfaction. Inter- 
estingly, in the paradigm used by this group, a kind of physiological substrate was identified (Jacobson \& Gottman, 1999). Although causality was not implied in these results, when one spouse rated videotapes of the other spouse, if the rater's physiological responses matched those of the spouse being observed on the video, the rater was more accurate in predicting the target spouse's feelings.

Another example of relationships as regulators is that social interaction moderates the relationship between depressive mood and heart rate variability (HRV) or vagal activity (indicators of calmness) (Schwerdtfeger \& Friedrich-Mai, 2009). In this study, when depressed individuals were alone, they showed lower HRV and more negative affect. When they were interacting with a partner, family member or friend, their HRV increased, as did their positive affect. The control group's social interactions with strangers or colleagues, on the other hand, were not accompanied by higher HRV.

\section{Biochemical Regulation}

Perhaps the earliest signs of biochemical regulation can be seen in the mirroring of the mother's prenatal biochemical profile by the neonate. In several studies we have documented similar biochemical profiles between pregnant women (both depressed and non-depressed) and their neonates including norepinephrine, serotonin, dopamine and cortisol (see Field, Diego \& Hernandez-Reif, 2010, for a review). Functional magnetic resonance imaging has shown that romantic love in adults activated dopamine-rich areas of the brain associated with reward and motivation in at least one study (Aron et al., 2005). Romantic relationships have also been accompanied by increased nerve growth factor and increased cortisol, but also by increased oxytocin (Loving, Crockett, \& Paxson, 2009). In another study, physical contact between couples contributed to oxytocin increases, which was not surprising, as the oxytocin responses to physical contact are connected to dopaminergic reward systems (Young \& Wang, 2004). As oxytocin increased, parasympathetic activity (calmness) increased and cortisol decreased. Those with more positive emotions and better sleep had better health. These data suggest questions for further research including "how co-regulation develops?" and "how similar partners' biochemical profiles become?”

\section{Dysregulation and Its Consequences for Health and Immune Function}

In a two-factor model, Gottman and Levenson (2002) suggested two patterns that lead to dysregulation in couples including an emotionally inexpressive pattern that is low in both positive and negative affect (those being later divorcing couples) and an emotionally volatile attack-defend pattern (those leading to earlier divorce). They labeled the pattern of negativity the "four horsemen of the apocalypse," (the four horsemen being criticism, defensiveness, contempt and stonewalling). Elsewhere, Gottman and his colleagues described dysregulated interactions as being high in negative affect, with heightened arousal levels playing a role in the poor health of individuals in distressed marriages (Jacobsen \& Gottman, 1999).

Much of the work on the impact of poor relationships on the immune system comes from Kiecolt-Glaser and her colleagues. In one of their papers, they suggested that three primary physiological pathways mediate the relationship between stressful social relationships and health, those being cardiovascular, ne- uroendocrine and immune function (Robles \& Kiecolt-Glaser, 2003). Increased blood pressure and heartrate accompanied aroused interactions. In contrast, daily contact between those with a good relationship led to decreased diastolic blood pressure. Others have noted decreases in both systolic and diastolic blood pressure in those having daily interactions (Gump, Polk, Kamarck, \& Shiffman, 2001; Holt-Lunstad, Uchino, Smith, Olson-Cerny, \& Nealey-Moore, 2003). In the Robles and Kiecolt-Glaser (2003) study, aroused interactions were also associated with elevated epinephrine, norepinephrine, cortisol, ACTH and growth hormone as well as decreased prolactin. Negative interactions contributed to $20 \%$ of the variance in the change in cortisol. In turn, there was a decrease in natural killer cells. Ironically, impaired immune function has continued into separation and divorce following a negative relationship including higher antibody titres to the Epstein-Barr virus and decreased natural killer cell activity (Powell, Lovallo, Matthews, Meyer, Midgley, Baum et al., 2002). Increased inflammatory cytokine production has also been noted (Black, 2002). This may relate to the negative effects of continuing intrusive thoughts about the distressed relationship and/or the loss of physical contact and its interpersonal regulation effects (Field, 2009). Poorer health habits, of course, confound the physiological effects on immune function.

\section{Similarity of Partners}

It is not clear how partner relationships become co-regulated. One possibility is that partners become increasingly similar across time so that one person is the reflection of the other, and each becomes easier to read so as to feel co-regulated (Soto \& Levenson, 2009). These researchers showed that over time the individuals of satisfied couples become increasingly similar in their behavior, suggesting that similarity contributes to a positive marital status. Others have suggested that similarity between partners attracts them to each other in the first place and leads to more persistent relationships versus breakups (Rusbalt, Kumashiro, Kubacka, \& Finkel, 2009).

Some have theorized that when children and adults interact frequently with a given peer, they come to behave in similar ways, and, in this way, they become physiologically attuned to each other (Chapple, 1970; Warner, 1979). Colloquial expressions characterize interaction synchrony between close friends as "being in tune with each other" or "being on the same wavelength". However, very little research has been conducted on the process whereby close friends become attuned to each other's behavior.

As Chapple (1970) theorized, each person in a close friend dyad has a preferred "interaction tempo" that has been described in terms of simple parameters such as cycle length and percent time spent active. The partners are thought to influence each other's interaction tempos as they converse and try to achieve smooth coordination. As Chapple (1970) has suggested, similarities of their interaction tempo make this an easier task, with partners becoming easily entrained to their interaction cycles. The example he gives is that the cycle length for speaker A would equal the length of speaker B with the percent time talking totaling $100 \%$. In those dyads, interactions would be enjoyable, and the partners would be attracted to each other. However, if the partners found it difficult to achieve smooth coordination of cycles, resulting in long mutual pauses and/or constant interruptions, they would then find their interactions 
less pleasant. This theory would suggest that as there is greater coupling between partners' behaviors and physiology, there would be more positive affect and a greater liking between partners. However, this theory needs further testing.

Older couples are reputedly less aroused and express more positive affect, which may relate to their longer relationships and greater familiarity with each other (Levenson et al., 1994). They are also more physically affectionate (Gottman, Coan, Carrère, \& Swanson, 1998). More physical touch might enable greater sensitivity to reading each other's signals and thereby greater attunement (Field, 2010b). Still another characteristic of older couples is that they display more humor which has been related to greater happiness (Jacobson \& Gottman, 1999). Couple humor in particular has been associated with more affectionate and playful interactions in older couples (Driver \& Gottman, 2004).

\section{Gender Differences}

Throughout the literature, gender differences have been noted for regulation, dysregulation and immune consequences. Men reportedly have more negative affect which is correlated with greater physiological arousal in men but not in women (Levenson et al., 1994). Typically, when a male initiates an issue, he notices his partner's negative response at a much lower threshold than a woman does, and men become more angry than women when presenting an issue, making physiological reactivity a greater issue for men than for women (Gottman et al., 2003). It is not surprising, then, that men experience greater immune dysfunction (Robles \& Kiecolt-Glaser, 2003). In contrast, if the marriage is distressed, women are more likely to experience health-related problems (Jacobsen \& Gottman, 1999). This may relate to men being more attuned to their own physiology and generally avoiding marital conflict discussions whereas women are noted to start over $80 \%$ of marital conflict discussions (Levenson et al., 1994).

\section{Potential Underlying Mechanisms/Mediators}

It is not clear how the synchrony/coherence/concordance patterns occur or what happens if they don't occur. Potential underlying mechanisms for coherence/concordance patterns include mirror neurons, affective priming, imitation and empathy. As was noted by Papousek (2007), Rizzolatti and co-workers have detected so-called mirror-neuron networks in the premotor cortex of non-human primates which function to control goaldirected or intentional action, but which are also activated and resonate when a primate merely observes a conspecific or a human carrying out the same goal-directed action (Rizzolatti, Fadiga, Gallese, \& Fogassi, 1996). According to neuroimaging studies in adults and studies using event-related potentials in infants, mirror neuron systems also exist and function in human brains and most likely also in the brains of preverbal infants (Arbib, 2005; Bauer, 2005; Rizzolatti, Fadiga, Fogassi, \& Gallese, 2002). They are currently discussed as the evolutionary basis for human empathy, affective resonance, understanding attention and intentions, observational learning and language acquisition. They may also provide the neurobiological basis for the phenomenon of newborn imitation, of mutual facial and vocal mirroring, immediate coupling of perception and action, and of early intersubjective affective sharing. Affective priming has also been suggested as a kind of automatic response of positive affect to an attachment figure (Banse, 1999), but failed to reveal individual differences related to relationship satisfaction. And empathy, or the accurate perception of signals has also been suggested as a cross-cultural mechanism, although physiological linkages appear to be less cross- cultural (Soto \& Levenson, 2009).

Potential mediators such as early imitation appear to exist across species, although they take different behavior forms. For examples, Suomi and his colleagues have demonstrated imitation of facial gestures including lip smacking, tongue protrusions, mouth opening, hand opening and open/closing of eyes (control condition) in neonatal rhesus macaques (Ferrari, Visalberghi, Paukner, Fogassi, Ruggiero, \& Suomi, 2006). The mother macaques were thought by Suomi and his colleagues to facilitate this imitation by their exaggerated facial expressions, speech, mutual gaze and body contact (Ferrari, Paukner, Ionica, \& Suomi, 2009). They further labeled this as "regulation of infant emotions" and as a precursor of more complex forms of social exchange including perspective-taking and empathy (Ferrari, Paukner, Ruggiero, Darcy, Unbehagen et al., 2009). In another monkey species, they reported that Capuchin monkeys preferred human imitators over non-imitators (Paukner, Suomi, Visalberghi, \& Ferrari, 2009). The monkeys, for example, looked longer at imitators and spent more time in proximity to imitators.

The first report of human neonatal imitation by Meltzoff and Moore (1977) showed neonates imitating tongue protrusion followed by research we conducted demonstrating imitation of exaggerated facial expressions including happy, sad and surprised faces (Field, Woodsen, Greenberg, \& Cohen, 1982). Althouth these data were subsequently replicated (Heimann, Laberg \& Nordoen, 2006). It is not surprising that imitation occurs in the human neonate given the already described studies by Suomi and his colleagues on imitation by infant monkeys, although considerable controversy has existed in the literature on neonatal imitation for several years. As Suomi (2006) suggested, humans often unconsciously and unintentionally imitate the behaviors of others during social interactions, which appears to increase rapport, liking and empathy between interaction partners (Paukner et al., 2009). They further suggested that this behavior matching leads to prosocial behavior towards others and may have been "one of the mechanisms at the basis of altruistic behavioral tendencies in the Capuchin monkeys and in other primates including humans” (Paukner et al., 2009).

\section{Epigenetic Programming May Contribute to Individuals' Rhythms and the Attraction to Others' Rhythms as Regulators}

Epigenetic programming or the process whereby "the environment interacts with the genome to produce individual differences in the expression of specific traits" has been advanced by Meaney and his colleagues (e.g. Bagot \& Meaney, 2010). According to Meaney and his group, the genome is programmed by the epigenome. Epigenetic 'mechanisms' are thought to mediate the effects of behavioral and environmental exposures early in life, as well as susceptibility to disease later in life. They suggest that in contrast to genetic sequence differences, epigenetic aberrations are potentially reversible, raising the possibility of interventions reversing epigenetic programming problems (Szyf \& Meaney, 2008).

Meaney and his colleagues have noted that adult rat offspring 
of mothers who showed greater pup licking/grooming had greater hippocampal glucocorticoid receptor expression, more complex dendritic structure and enhanced synaptic potentiation (van Hasselt et al., 2011). The authors suggested, however, that this literature has been based on studies where the total amount of maternal care was directed towards the entire litter, thus ignoring any potential for in-litter variation. In their study, individual differences were noted in the amount of licking/ grooming provided to individual pups (van Hasselt et al., 2011). The pup licking/grooming score was positively correlated with the already mentioned brain development variables, suggesting that even moderate variability in early environments significantly affected adult hippocampal function. These effects have been reversed by cross-fostering, suggesting that they are determined by epigenetic rather than genetic processes (McGowan, Suderman, Sasaki, Huang, Hallett et al., 2011). Further, variations of maternal behavior in the rat model have been associated with differences in estrogen-oxytocin interactions and in dopamine levels which are involved in the establishment and maintenance of social bonds (Shahrokh, Zhang, Diorio, Gratton, \& Meaney, 2010). And, post-weaning isolation reduced maternal licking/grooming and oxytocin receptor binding in the offspring of high licking/grooming mothers, whereas social enrichment enhanced exploration, licking/grooming behavior and oxytocin receptor binding in low licking/grooming mothers (Champagne \& Meaney, 2007).

In several different studies, Meaney and his colleagues identified more than 900 genes that were stably regulated by maternal care (Weaver, Meaney, \& Szyf, 2006). As this group suggested, these studies "define a biological basis for the interplay between environmental signals and the genome in the regulation of individual differences in behavior, cognition and physiology” (Zhang \& Meaney, 2010). The generalization of this process across species and across development, however, needs to be tempered by the observation that there is also research showing differences across strains of the rat model and epigenetic programming (Lester, Tronick, Nestler, Abel, Kosofsky et al., 2011).

Nonetheless, this research highlights the epigenetic programming that may occur in early mother-infant interactions. This may explain why mother-peer-reared monkeys are less affected by stressors than peer-reared or surrogate-peer-reared monkeys (Dettmer, Novak, Suomi, \& Meyer, 2011). Suomi and his colleagues also referred to gene-environment interactions throughout development with respect to Rhesus monkeys and humans (see Suomi, 2006 for a review). An example of their research is that the short allele of the serotonin transporter gene is associated with deficits in neurobehavioral functioning during infancy and in poor controlled aggression and low serotonin metabolism throughout juvenile and adolescent development in monkeys who are reared with peers but not in monkeys who are reared with their mothers and peers during infancy. Long serotonin alleles appeared to dampen the adverse early attachment relationships while "maternal buffering" appeared to reduce the risk for those with the short alleles (Suomi, 2006).

Similar examples of maternal care as potential epigenetic programming appear in the early mother-infant and fatherinfant literature including our research on enhanced growth and development in those infants receiving massage (see Field, 2010a, for a review). And, early interactions have been facilitated by touch, imitation and sensitive reading of cues by parents, most especially in high-risk infants such as preterm in- fants and infants of depressed mothers. The still-face (mother remaining still-faced) interaction has been used as a model for simulating maternal depression effects. Feldman and her colleagues illustrated maternal touch as a regulator during their still-face interactions (Feldman, Singer, \& Zagoory, 2010). This paradigm of adding mother touch to reduce infant stress during the still-face situation has been effectively used by both nondepressed (Pelaez-Nogueras, Gewirtz, Field, Cigales, Malphurs et al., 1996b) and depressed mothers (Field et al., 2007; Pelaez-Nogueras, Field, Hossain, \& Pickens, 1996a). In still another still-face study, cortisol reactivity was higher in infants during the still-face condition, and cortisol levels were lower for infants in the still-face plus maternal touch condition (Feldman et al., 2007). Vagal tone was also lower during the still-face than the still-face plus maternal touch interaction. Maternal touch was associated with higher infant vagal tone and lower maternal and infant cortisol. Others have noted that regulatory touching occurs naturally on the part of the mothers when they are asked to remain still-faced (Jean \& Stack, 2009). In the Jean and Stack (2009) study, mothers used more nurturing touch when their infants were distressed during the stillface period.

Interaction coaching techniques have been used to help improve the interactions of high-risk dyads, for example, the interactions of mothers and their preterm infants whose cues are more difficult to read and the interactions of infants and their depressed mothers who are less attentive to their infants' signals. Examples of interaction coaching are asking the mothers to imitate their infants' behaviors and to be silent during gaze aversion when the infant appears to be highly aroused, and to simplify their behaviors by repetition (Field, 1983). These techniques seem to sensitize the mothers to their infants' gaze and affect and thereby diminish the infants' gaze aversion and fussiness as well as facilitate their attentiveness and positive affect such as smiling and laughing. In this way, the mother or father and infant can become attuned to each other, and their interactions become more harmonious. Effectively, in these interventions the parent is being taught to provide optimal stimulation and arousal modulation.

\section{Future Directions}

Relationships may not work because as in oscillators, individuals may not be on the same wavelength. This may relate to their having different thresholds for stimulation as well as arousal modulation. Chapple's work exemplifies how some individuals are more disturbed by being interrupted and being "talked over" versus some who are more disturbed by the latent responding of a confederate (Chapple, 1970). Other examples are depressed mothers being unresponsive due to their high thresholds to their infant's stimulation and preterm infants being unresponsive to the mothers because of their high thresholds for stimulation. Individual differences may exist in thresholds of partners who break up as in one being too sensitive, i.e. having a low threshold while the other may be too insensitive, i.e. having a high threshold. More laboratory research is needed on measuring the streams of behavior and physiological responding in natural interactions as opposed to the conflict-like interactions studied by Gottman and his colleagues (Gottman et al., 1992, 1998, 2002, 2003). And, laboratory interventions, e.g. biofeedback-interactions as in observing one's physiological responses and bug-in-the-ear interaction feedback, might be 
informative as to how flexible and responsive disturbed relationships are to change. The stream of emotions from extremely positive (highly energized, fast-paced talking with laughter) to sober, reflective slow-paced talking, to highly charged angry exchanges may need to be modulated by both partners simultaneously. And, the highly positive to highly negative interactions may be less arousing/dysregulating in the presence of physical contact, just as the mother holds the crying infant to comfort and soothe. This behavior/physiology could be simultaneously measured to determine more precise ways in which relationships might serve as regulators.

\section{Summary}

In summary, Hofer $(1984,1996)$ and Field $(1985,1994)$ advanced models on relationships as regulators, with Hofer supporting his model by data on infant rats separated from their mothers and Field describing a psychobiological attunement between human infants and their mothers. Many studies on relationships have focused on temporary separations and loss associated with death and breakups, although both Hofer and Field suggested that the real question is "what was there about the relationship that was then missing after the loss?" Some studies have addressed that question by looking at good vs. less good relationships. Examples of these given in this review include relationships between non-depressed versus depressed mothers and their infants, preschool and preadolescent friends versus acquaintances, and happily versus less happily married couples. Some behavioral and physiological data support Hofer's and Field's "relationships as regulators" model, although very little is known about the underlying mechanisms for relationships as regulators. Further research is needed on the potential mediators reviewed here, including mirror neurons, affective priming, imitation and empathy as well as the epigenetic programming that may contribute to relationships as regulators across species and across development. Further, research is needed on the development of the individual's rhythms and the attraction and adjustment to others' rhythms as regulators in relationships.

\section{Acknowledgements}

We would like to thank those who participated in our studies. This research was supported by a merit award (MH46586) NIH grants (AT00370 and HD056036) and Senior Research Scientist Awards (MH00331 and AT001585) and a March of Dimes Grant (12-FYO3-48) to Tiffany Field and funding from Johnson \& Johnson Pediatric Institute to the Touch Research Institute.

\section{REFERENCES}

Arbib, M. (2005). From monkey-like action recognition to human language: An evolutionary framework for neurolinguistics. Behavioral and Brain Sciences, 28, 105-124. doi:10.1017/S0140525X05000038

Aron, A., Fisher, H., Mashek, D. J., Strong, G., Li, H., \& Brown, L. L. (2005). Reward, motivation, and emotion systems associated with early-stage intense romantic love. Journal of Neurophysiology, 94, 327-337. doi:10.1152/jn.00838.2004

Bagot, R. C., \& Meaney, M. J. (2010). Epigenetics and the biological basis of gene $\mathrm{x}$ environment interactions. Journal of American Academy of Child Adolescence Psychiatry, 49, 752-771.

doi:10.1016/j.jaac.2010.06.001
Banse, R. (1999). Automatic Evaluation of self and significant others: Affective priming in close relationships. Journal of Social and Personal Relationships, 16, 803-821. doi:10.1177/0265407599166007

Bauer, J. (2005). Warum ich fühle, was du fühlst. Intuitive Kommunikation und das Geheimnis der Spiegelneurone. Hamburg: Hoffmann und Campe.

Black, P. H. (2002). Stress and the inflammatory response: A review of neurogenic inflammation. Brain, Behavior and Immunity, 16, 622653. doi:10.1016/S0889-1591(02)00021-1

Bowlby, J. (1982). Attachment and loss: Vol. 1 attachment (2nd ed.). New York: Basic Books.

Carrère, S., \& Gottman, J. M. (1999). Predicting divorce among newlyweds from the first three minutes of a marital conflict discussion. Family Process, 38, 293-301. doi:10.1111/j.1545-5300.1999.00293.x

Champagne, F. A., \& Meaney, M. J. (2007). Transgenerational effects of social environment on variations in maternal care and behavioral response to novelty. Behavioral Neuroscience, 121, 1353-1363. doi:10.1037/0735-7044.121.6.1353

Chapple, E. D. (1970). Culture and biological man: Exploration in behavioral anthropology. New York: Holt, Rinehart \& Winston.

Chen, Z., Williams, K. D., Fitness, J., \& Newton, N. C. (2008). When hurt will not heal: Exploring the capacity to relive social and physical pain. Psychological Science, 19, 789-795. doi:10.1111/j.1467-9280.2008.02158.X

Diamond, L. M., Hicks, A. M., \& Otter-Henderson, K. (2008). Every time you go away: Changes in affect, behavior, and physiology associated with travel-related separations from romantic partners. Journal of Personality and Social Psychology, 95, 385-403. doi:10.1037/0022-3514.95.2.385

Dettmer, A. M., Novak, M. A., Suomi, S. J., \& Meyer, J. S. (2011). Physiological and behavioral adaption to relocation stress in differentially reared rhesus monkeys: Hair cortisol as a biomarker for anxiety-related responses. Psychoneuroendocrinology, Epub ahead of print.

Driver, J. L., \& Gottman, J. M. (2004). Daily marital interactions and positive affect during marital conflict among newlywed couples. Family Process, 43, 301-314. doi:10.1111/j.1545-5300.2004.00024.x

Eisenberger, N. I., Lieberman, M. D., \& Williams, K. D. (2003). Does rejection hurt? An fMRI study of social exclusion. Science, 302, 290-292. doi:10.1126/science.1089134

Feldman, R., \& Eidelman, A. I. (2007). Maternal postpartum behavior and the emergence of infant-mother and infant-father synchrony in preterm and full-term infants: The role of neonatal vagal tone. $D e$ velopmental Psychobiology, 49, 290-302. doi:10.1002/dev.20220

Feldman, R., Singer, M., \& Zagoory, O. (2010). Touch attenuates infants' physiological reactivity to stress. Developmental Science, 13, 271-278. doi:10.1111/j.1467-7687.2009.00890.x

Feldstein, S., \& Field, T. (2002). Vocal behavior in the dyadic interactions of preadolescent and early adolescent friends and acquaintances. Adolescence, 37, 495-513.

Ferrari, P. F., Paukner, A., Ionica, C., \& Suomi, S. J. (2009). Reciprocal face-to-face communication between rhesus macque mothers and their newborn infants. Current Biology, 19, 1768-1772. doi:10.1016/j.cub.2009.08.055

Ferrari, P. F., Paukner, A., Ruggiero, A., Darcey, L., Unbehagen, S., \& Suomi, S. J. (2009). Interindividual differences in neonatal imitation and the development of action chains in rhesus macques. Child Development, 80, 1057-1068. doi:10.1111/j.1467-8624.2009.01316.X

Ferrari, P. F., Visalberghi, E., Paukner, A., Fogassi, L., Ruggiero, A., \& Suomi, S. J. (2006). Neonatal imitation in rhesus macaques. PLoS Biology, 4, e302. doi:10.1371/journal.pbio.0040302

Field, T. (1983). Early interactions and interaction coaching of highrisk infants and parents. In M. Perlmutter (Ed.), Minnesota symposium on child psychology. Hillsdale, NJ: Lawrence Erlbaum Associates.

Field, T. (1985). Attachment as psychobiological attunement: Being on the same wavelength. In M. Reite, \& T. Field (Eds.), Psychobiology of attachment and separation. New York: Academic Press.

Field, T. (1991). Young children's adaptations to repeated separations 
from their mothers. Child Development, 62, 539-547.

doi:10.2307/1131129

Field, T. (1994). The effects of mother's physical and emotional unavailability on emotion regulation. Monographs of the Society for Research in Child Development, 59, 208-227. doi:10.2307/1166147

Field, T. (2007). The Amazing infant. London: Blackwell.

Field, T. (2009). Heartbreak. New York: Xlibris.

Field, T. (2010a). Postpartum depression effects on early interactions, parenting and safety practices: A review. Infant Behavior and Development, 33, 1-6. doi:10.1016/j.infbeh.2009.10.005

Field, T. (2010b). Touch for socioemotional and physical well-being: A review. Developmental Review, 30, 367-383. doi:10.1016/j.dr.2011.01.001

Field, T., Diego, M., \& Hernandez-Reif, M. (2010). Prenatal depression effects and interventions: A review. Infant Behavior and Development, 33, 409-418.

Field, T., Diego, M., Pelaez, M., Deeds, O., \& Delgado, J. (2009). Breakup distress in university students. Adolescence, 44, 705-727.

Field, T., Diego, M., Pelaez, M., Deeds, O., \& Delgado, J. (2010). Breakup distress and the loss of intimacy in university students. Psychology, 1, 173-177. doi:10.4236/psych.2010.13023

Field, T., Diego, M., Pelaez, M., Deeds, O., \& Delgado, J. (2010a). Intrusive thoughts: A primary variable in breakup distress. College Student Journal, in press.

Field, T., Diego, M., Pelaez, M., Deeds, O., \& Delgado, J. (2010b). Negative emotions and behaviors are markers for breakup distress. College Student Journal, in press.

Field, T., Greenwald, P., Morrow, C., Foster, T., Guthertz, M. et al. (1992). Behavior state matching during interactions of preadolescent friends versus acquaintances. Developmental Psychology, 28, 242250. doi:10.1037/0012-1649.28.2.242

Field, T., Healy, B., Goldstein, S., \& Guthertz, M. (1990). Behavior state matching and synchrony in mother-infant interactions of nondepressed versus depressed dyads. Developmental Psychology, 26, 7-14. doi:10.1037/0012-1649.26.1.7

Field, T., Healy, B., \& LeBlanc, W. (1989). Sharing and synchrony of behavior states and heart rate in nondepressed versus depressed mother-infant interactions. Infant Behavior and Development, 12, 357-376. doi:10.1016/0163-6383(89)90044-1

Field, T., Hernandez-Reif, M., Diego, M., Feijo, L., Vera, Y. et al. (2007). Still-face and separation effects on depressed mother-infant interactions. Infant Mental Health Journal, 28, 314-323. doi:10.1002/imhj.20138

Field, T., \& Reite, M. (1984). Children's responses to separation from mother during the birth of another child. Child Development, 55, 1308-1316. doi:10.2307/1130000

Field, T., Schanberg, S. M., Scafidi, F., Bauer, C. R., Vega-Lahr, N. et al. (1986). Tactile/kinesthetic stimulation effects on preterm neonates. Pediatrics, 77, 654-658.

Field, T., Vega-Lahr, N., \& Jagadish, S. (1984). Separation stress of nursery school infants and toddlers graduating to new classes. Infant Behavior and Development, 7, 527-530. doi:10.1016/S0163-6383(84)80012-0

Field, T., Woodson, R., Greenberg, R., \& Cohen, D. (1982). Discrimination and imitation of facial expressions by neonates. Science, 218, 179-181. doi:10.1126/science.7123230

Geoffroy, M. C., Cote, S. M., Parent, S., \& Seguin, J. R., (2006). Daycare attendance, stress, and mental health. Canadian Journal of Psychiatry, 51, 607-615.

Goldstein, S., Field, T., \& Healy, B. (1989). Concordance of play behavior and physiology in preschool friends. Journal of Applied Developmental Psychology, 10, 337-351. doi:10.1016/0193-3973(89)90034-8

Gottman, J. M., Coan, J., Carrère, S., \& Swanson, C. (1998). Predicting marital happiness and stability from newlywed interactions. Journal of Marriage and the Family, 60, 5-22. doi:10.2307/353438

Gottman, J. M., \& Levenson, R. W. (1992). Marital processes predictive of later dissolution: Behavior, physiology, and health. Journal of Personality and Social Psychology, 63, 221-233. doi:10.1037/0022-3514.63.2.221

Gottman, J. M., \& Levenson, R. W. (2002). A two-factor model for predicting when a couple will divorce: Exploratory analyses using 14-year longitudinal data. Family Process, 41, 83-96. doi:10.1111/j.1545-5300.2002.40102000083.x

Gottman, J. M., Levenson, R. W., Swanson, C., Swanson, K., Tyson, R., \& Yoshimoto, D. (2003). Observing gay, lesbian and heterosexual couples' relationships: mathematical modeling of conflict interaction. Journal of Homosexuality, 45, 65-91. doi:10.1300/J082v45n01 04

Gump, B. B., Polk, D. E., Kamarck, T. W., \& Shiffman, S. M. (2001). Partner interactions are associated with reduced blood pressure in the natural environment: Ambulatory monitoring evidence from a healthy, multiethnic adult sample. Psychosomatic Medicine, 63, 423-433.

Heimann, M., Laberg, K. E., \& Nordoen, B. (2006). Imitative interaction increases social interest and elicited imitation in non-verbal children with autism. Infant and Child Development, 15, 297-309. doi:10.1002/icd.463

Heron, W. (1961). Cognitive and physiological effects of perceptual isolation. In P. Solomon (Ed.), Sensory deprivation. Cambridge, Massachusetts: Harvard University Press.

Hofer, M. (1984). Relationships as regulators: A psychobiologic perspective on bereavement. Psychosomatic Medicine, 46, 183-197.

Hofer, M. (1996). On the nature and consequences of early loss. Psychosomatic Medicine, 58, 570-581.

Holt-Lunstad, J., Uchino, B. N., Smith, T. W., Olson-Cerny, C., \& Nealey-Moore, J. B. (2003). Social relationships and ambulatory blood pressure: Structural and qualitative predictors of cardiovascular function during everyday social interactions. Health Psychology, 22, 388-397. doi:10.1037/0278-6133.22.4.388

Jacobson, N. S., \& Gottman, J. M. (1999). When men batter women. New York: Simon \& Schuster.

James, W. (1950). The principles of psychology (Vol. 1). New York: Dover.

Jean, A. D., \& Stack, D. M. (2009). Functions of maternal touch and infant's affect during face-to-face interactions: New directions for the still-face. Infant Behavior \& Development, 32, 123-128. doi:10.1016/j.infbeh.2008.09.008

Klein, K. E., \& Wegmann, H. M. (1974). The resynchronization of human circadian rhythms after transmediterranean flights as a result of flight direction and mode of activity. In L. E. Scheving, F. Halberg, \& J. F. Pauly (Eds.), Chronobiology (pp. 564-570). Tokyo: Igaku Shoin.

Lester, B. M., Tronick, E., Nestler, E., Abel, T., Kosofsky, B. et al. (2011). Behavioral epigenetics. Annals of the New York Academy of Sciences, 1226, 14-33. doi:10.1111/j.1749-6632.2011.06037.x

Levenson, R. W., Carstensen, L. L., \& Gottman, J. M. (1994). The influence of age and gender on affect, physiology, and their interrelations: A study of long-term marriages. Journal of Personality and Social Psychology, 67, 56-68. doi:10.1037/0022-3514.67.1.56

Levenson, R. W., \& Gottman, J. M. (1983). Marital interaction: Physiological linkage and affective exchange. Journal of Personality and Social Psychology, 45, 587-597. doi:10.1037/0022-3514.45.3.587

Levenson, R. W., \& Gottman, J. M. (1985). Physiological and affective predictors of change in relationship satisfaction. Journal of Personality and Social Psychology, 49, 85-94.

doi:10.1037/0022-3514.49.1.85

Loving, T. J., Crockett, E. E., \& Paxson, A. A. (2009). Passionate love and relationship thinkers: Experimental evidence for acute cortisol elevations in women. Psychoneuroendocrinology, 34, 939-946. doi:10.1016/j.psyneuen.2009.01.010

Mason, W. A., \& Berkson, G. (1975) Effects of maternal mobility on the development of rocking and other behaviors in rhesus monkeys: A study with artificial mothers. Developmental Psychobiology, 8, 197-221. doi:10.1002/dev.420080305

McClintock, M. K. (1983) Pheromonal regulation of the ovarian cycle: Enhancement, suppression, and synchrony. In J. G. Vandenberg (Ed.), Pheromones and reproduction in mammals (pp. 113-149). New York: Academic Press.

McGowan, P. O., Suderman, M., Sasaki, A., Huang, T. C., Hallett, M. 
et al. (2011). Broad epigenetic signature of maternal care in the brain of adult rats. PLoS One, 6, e14739.

doi:10.1371/journal.pone.0014739

Meltzoff, A. N., \& Moore, M. K. (1977). Imitation of facial and manual gestures by human neonates. Science, 198, 75-78. doi:10.1126/science.198.4312.75

Monk, T. H., Burk, L. R., Klien, M. H., Kupfer, D. J., Soehner, A. M., \& Essex, M. J. (2010). Behavioral circadian regularity at age 1 month predicts anxiety levels during school-age years. Psychiatry Research, 178, 370-373. doi:10.1016/j.psychres.2009.09.020

Monk, T. H., Houck, P. R., \& Shear, M. K. (2005). The daily life of complicated grief patients-What gets missed, what gets added? Death Studies, 30, 77-85. doi:10.1080/07481180500348860

Montagner, H., Restoin, A., \& Henry, J. C. (1982). Biological defense rhythms, stress and communications in children. In W. W. Hartup (Ed.), Review of child development research. Chicago: University of Chicago Press.

Papousek, M. (2007). Communication in early infancy: An arena of intersubjective learning. Infant Behavior \& Development, 30, 258266. doi:10.1016/j.infbeh.2007.02.003

Paukner, A., Suomi, S. J., Visalberghi, E., \& Ferrari, P. F., (2009). Capuchin monkeys display affiliation toward humans who imitate them. Science, 325, 880-883. doi:10.1126/science.1176269

Pelaez, M., Field, T., Diego. M., Deeds, O., \& Delgado, J. (2011). Insecurity, controlling, and loss of interest behaviors relate to breakup distress in university students. College Student Journal, 452.

Pelaez-Nogueras, M., Field, T., Hossain, Z., \& Pickens, J. (1996a). Depressed mothers' touching increases infants' positive affect and attention in still-face interactions. Child Development, 67, 17801792. doi:10.2307/1131731

Pelaez-Nogueras, M., Gewirtz, J. L., Field, T., Cigales, M., Malphurs, J., Clasky, S., \& Sanchez, A. (1996b). Infant preference for touch stimulation in face-to-face interactions. Journal of Applied Developmental Psychology, 17, 199-213. doi:10.1016/S0193-3973(96)90025-8

Powell, L. H., Lovallo, W. R., Matthews, K. A., Meyer, P., Midgley, A. R., Baum, A. et al. (2002). Physiologic markers of chronic stress in premenopausal, middle-aged women. Psychosomatic Medicine, 64, 502-509.

Rizzolatti, G., Fadiga, L., Fogassi, L., \& Gallese, V. (2002). From mirror neurons to imitation: Facts and speculations. In A. N. Meltzoff, \& W. Prinz (Eds.), The imitative mind. Cambridge: Cambridge University Press.

Rizzolatti, G., Fadiga, L., Gallese, V., \& Fogassi, L. (1996). Premotor cortex and the recognition of motor actions. Cognitive Brain Research, 3, 131-141.

Robles, T. F., \& Kiecolt-Glaser, J. K. (2003). The physiology of marriage: Pathways to health. Physiology and Behavior, 79, 409-416. doi:10.1016/S0031-9384(03)00160-4

Roopnarine, J. L., \& Field, T. M. (1984). Play behaviors of friends and acquaintances in nursery school. In T. Field, J. Roopnarine, \& M. Segal (Eds.), Friendships in normal and handicapped children. Norwood, NJ: Ablex.

Rusbult, C. E., Kumashiro, M., Kubacka, K. E., \& Finkel, E. J. (2009). "The part of me that you bring out": Ideal similarity and the Michelangelo phenomenon. Journal of Personality and Social Psychology, 96, 61-82. doi:10.1037/a0014016

Sbarra, D. A., \& Hazan, C. (2008). Coregulation, dysregulation, selfregulation: An integrative analysis and empirical agenda for understanding adult attachment, separation, loss, and recovery. Personality and Social Psychology Review, 12, 141-167. doi:10.1177/1088868308315702

Schanberg, S., \& Field, T. (1987). Sensory deprivation stress and supplemental stimulation in the rat pup and preterm human neonate, Child Development, 58, 1431-1447. doi:10.2307/1130683

Schwerdtfeger, A. \& Friedrich-Mai, P. (2009). Social interaction mod- erates the relationship between depressive mood and heart rate variability: Evidence from an ambulatory monitoring study. Health Psychology, 28, 501-509. doi:10.1037/a0014664

Shahrokh, D. K., Zhang, T. Y., Diorio, J., Gratton, A., \& Meaney, M. J. (2010). Oxytocin-dopamine interactions mediate variations in maternal behavior in the rat. Endocrinology, 151, 2276-2286. doi:10.1210/en.2009-1271

Shear, K., \& Shair, H. (2005). Attachment, loss, and complicated grief. Developmental Psychobiology, 47, 253-267. doi:10.1002/dev.20091

Singer, T., Seymour, B., O’Doherty, J., Kaube, H., Dolan, R. J., \& Frith, C. D. (2004). Empathy for pain involves the affective but not sensory components of pain. Science, 303, 1157-1162. doi:10.1126/science.1093535

Soto, J. A., \& Levenson, R. W. (2009). Emotion recognition across cultures: The influence of ethnicity on empathic accuracy and physiological linkage. Emotion, 9, 874-884. doi:10.1037/a0017399

Stern, D. N. (2004). The present moment in psychotherapy and everyday life. New York: Norton.

Suomi, S. J., (2006). Risk, resilience, and gene x environment interactions in rhesus monkeys. Annals of the New York Academy of Sciences, 1094, 52-62. doi:10.1196/annals.1376.006

Szyf, M., \& Meaney, M. J. (2008). Epigenetics, behavior, and health. Journal of Allergy and Clinical Immunology, 4, 37-49.

Trevarthen, C. (1979). Communication and cooperation in early infancy: A description of primary intersubjectivity. In M. Bullowa (Ed.), Before speech: The beginning of human communication (pp. 321-347). Cambridge: Cambridge University Press.

Tronick, E. Z. (2003). Things still to be done on the still-face effect. Infancy, 4, 475-482. doi:10.1207/S15327078IN0404_02

Van Hasselt, F. N., Corneliesse, S., Yuang Zhang, T., Meaney, M. J., Velzing, E. H. et al. (2011). Adult hippocampal glucocorticoid receptor expression and dentate synaptic plasticity correlate with maternal care received by individuals early in life. Hippocampus, Epub ahead of print.

Vermeer, H. J., \& Van Ijzendoorn, M. H. (2006). Children’s elevated cortisol levels at daycare: A review and meta-analysis. Early Child Research Quarterly, 21, 390-401. doi:10.1016/j.ecresq.2006.07.004

Wade, M. G., Ellis, M. J., \& Bohrer, R. E. (1973). Biorhythms in the activity of children during free play time. Journal of the Experimental Analysis of Behavior, 20, 155-162. doi:10.1901/jeab.1973.20-155

Warner, R. M. (1979). Periodic rhythms in conversational speech. Language and Speech, 22, 381-396.

Weaver, I. C. G., Cervoni, N., Champagne, F. A., Alessio, A. C. D., Sharma, S. et al. (2004). Epigenetic programming by maternal behavior. Nature Neuroscience, 7, 847-854.

doi:10.1038/nn1276

Weaver, I. C., Meaney, M. J., \& Szyf, M. (2006). Maternal care effects on the hippocampal transcriptome and anxiety-mediated behaviors in the offspring that are reversible in adulthood. Proceedings of the $\mathrm{Na}$ tional Academy of Science of United States of America, 103, 34803485. doi:10.1073/pnas. 0507526103

Weller, L., \& Weller, A. (1993). Human menstrual synchrony: A critical assessment. Neuroscience and Biobehavioral Reviews, 17, 427439. doi:10.1016/S0149-7634(05)80118-6

Wittstein, I. S. Thiemann, D. R., Lima, J. A. C., Baughman, Kt., Schulman, S. P., Gerstenblith, G. et al. (2005). Neurohumoral features of myocardial stunning due to sudden emotional stress. The New England Journal of Medicine, 352, 539-548. doi:10.1056/NEJMoa043046

Young, L. J., \& Wang, Z. (2004). The neurobiology of pair bonding. Nature Neuroscience, 7, 1048-1054. doi:10.1038/nn1327

Zhang, T. Y., \& Meaney, M. J. (2010). Epigenetics and the environmental regulation of the genome and its function. Annual Review of Psychology, 61, 439-466.

doi:10.1146/annurev.psych.60.110707.163625 